\title{
MORPHOLOGICAL CHANGES IN HUMAN FETAL SPLEEN AT DIFFERENT GESTATIONAL AGES
}

\section{Thomas $\mathrm{S}^{* 1}$, Sinha $\mathrm{DN}{ }^{2}$, Singh $\mathrm{AK}^{3}$, Deopa $\mathrm{D}^{4}$, Niranjan $\mathbf{R}^{5}$.}

${ }^{*}$ Assistant Professor, Department of Anatomy, Sri Ram Murti Smarak Institute of Medical sciences (SRMS IMS), Bhojipura, District- Bareilly, Uttar Pradesh-India.

2-5 Department of Anatomy, GMC Haldwani, Uttarakhand, India.

\section{ABSTRACT}

Background: The purpose of the study was desired to investigate and observe the variations in the morphology of spleen in human fetuses. The spleen is the largest secondary lymphoid organ, in the fetal stage it also performs the role of haematopoiesis. It acts as a blood filter, and also acts as storage site for iron, erythrocytes, and platelets.

Materials and Methods: This study has been carried out on spleen of 40 formalin preserved human fetuses (19 males and 21 females) of different gestational ages, in the Department of Anatomy, Government Medical College, Haldwani over a period of two years (i.e. 2014- 2016), with due regards on ethical grounds. Various gross parameters of spleen such as its location, shape, relations, notches \& fissures and ligaments were observed and the results were statistically analyzed.

Results: Spleens in all the fetuses was located in the left hypochondrium. $60 \%$ of the fetal spleens were wedge shaped. While stomach was related to the spleen in all the gestational ages, kidney and left colic flexure were not related to the spleen in the early age of the fetus. Liver and left adrenal gland also showed relations with the fetal spleen. Maximum number of notches was present in the superior border followed by inferior border and lateral pole. Fissures were also seen in 11 spleens.

Conclusion: Knowledge about prenatal ontogenesis of the spleen will help to understand the mechanisms of pathology in the organ and create methods of diagnosis and prevention.

KEY WORDS: Spleen, Morphology, Fetus, Wedge, Notches, Fissures.

Address for Correspondence: Dr Sonali Thomas, Assistant Professor, Department of Anatomy, Sri Ram Murti Smarak Institute of Medical sciences (SRMS IMS), Bhojipura, District- Bareilly (Uttar Pradesh-India). Pin code- 243002. E-Mail: sonathomas0017@gmail.com.

Access this Article online

Quick Response code

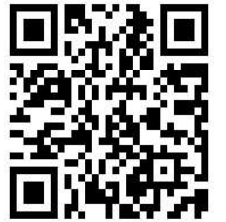

DOI: $10.16965 /$ ijar.2019.273

Journal Information

International Journal of Anatomy and Research

\begin{tabular}{|c|c|} 
ICV for 2016 \\
$\mathbf{9 0 . 3 0}$
\end{tabular}$\quad \begin{gathered}\text { ISSN (E) 2321-4287 | ISSN (P) 2321-8967 } \\
\text { https://www.ijmhr.org/ijar.htm } \\
\text { DOI-Prefix: https://dx.doi.org/10.16965/ijar }\end{gathered}$

Article Information

Received: 15 Jul 2019

Peer Review: 15 Jul 2019

Revised: None
Accepted: 19 Aug 2019

Published (O): 05 Sep 2019

Published (P): 05 Sep 2019

\section{INTRODUCTION}

The spleen (lien) is largest of the secondary lymphoid organ, consisting of an encapsulated mass of lymphoid and vascular tissue situated in the upper left quadrant of the abdominal cavity between the fundus of the stomach and the diaphragm [1]. The spleen appears at about $5^{\text {th }}$ week of intrauterine life as a mesenchymal condensation between the two layers of the dorsal mesogastrium $[2,3]$. At birth the weight of spleen is 13g [1]. The spleen has a superolateral diaphragmatic and inferomedial visceral surface. There are superior and inferior borders and anterior/inferior and posterior/ superior extremities or poles. The visceral surface is irregular and marked by gastric, renal, pancreatic and colic impression. 


\section{MATERIALS AND METHODS}

This work has been carried out on spleen of 40 human fetuses (19 males and 21 females) of gestational age ranging from $14^{\text {th }}$ to $40^{\text {th }}$ gestational weeks, in the Department of Anatomy, Government Medical College, Haldwani. The fetuses were obtained from the Department of Obstetrics and Gynaecology, Dr. Sushila Tiwari Hospital, Government Medical College, Haldwani (Uttarakhand) over a period of two years. With due regards on ethical grounds, the fetuses were preserved in $10 \%$ formalin by multiple injection method [4]. 24 hours after the procurement of the fetus, dissection was performed according to the standard protocol [5]. Spleen was displayed; gross parameters were observed and tabulated.

Various gross parameters of spleen were observed in situ such as:

\section{Location}

2. Shape (wedge/tetrahedral/triangular/oval/irregular).

3. Relations of spleen with other abdominal organs (such as liver, stomach, colon, pancreas, kidney, adrenal gland). Various impressions on visceral and diaphragmatic surfaces on the spleen were noted.

4. Three major ligaments of the spleen i.e. gastrosplenic, lienorenal and phrenicocolic ligaments were investigated.

5. Superior and inferior borders of spleen were investigated for the presence of notches or fissures and number of notches were recorded. On the basis of gestational age, sample of 40 human fetuses were further stratified into three groups: Group 1 (12- 24 weeks, $n=13$ ), group 2 (25- 36 weeks, $n=14$ ) and group 3 (37- 40 weeks, $\mathrm{n}=13$ )

Descriptive statistics was used to define all parameters. Each morphological and parameter was correlated with divided gestational age groups by using one way ANOVA test within and between the groups. Independent sample test ( $T$ test) was used to note sexual dimorphism. Frequency variables were taken for shape of spleen, spleen's hilum. P-value of $<0.05$ was considered significant and $P$ - value $<0.001$ was considered highly significant.

\section{OBSERVATION AND RESULTS}

Of the 40 fetal spleens studied, all of them were present in the left hypochondrium [Fig 1]. Majority of the fetal spleen was wedge shaped (60\%) (Fig 2) followed by tetrahedral (15\%), irregular (10\%), triangular (7.5\%), oval (5\%) and pyramidal (1\%) [Table 1,Fig 3].

The variable shapes of fetal spleen in different proportions were present in the group of $25-36 w k s$ gestational age. No association was found in the different shapes of the fetal spleen with that of the gestational age (Table 2).

Stomach was related to the visceral surface of the spleen in all the fetuses. The stomach impression was the largest and most concave, present between the superior border and the hilum. Left colic flexure and pancreas were related in $95 \%$ \& $92.5 \%$ fetuses respectively followed by left kidney in $85 \%$ cases (Fig 1 , Tab.3). The left adrenal gland was in contact with spleen in 7 out of 13 cases in the $2^{\text {nd }}$ trimester and was not in contact in the subsequent gestational ages. The liver and spleen were in contact in $25 \%$ of cases of which the percentage of contact was highest during 37- 40 weeks. There was no impression of ribs on the diaphragmatic surface.

Fig. 1: Photograph showing 23 weeks old dissected fetus with spleen in- situ position in the left hypochondrium and showing its relations with stomach (st), left colic flexure(c) and left kidney (k).

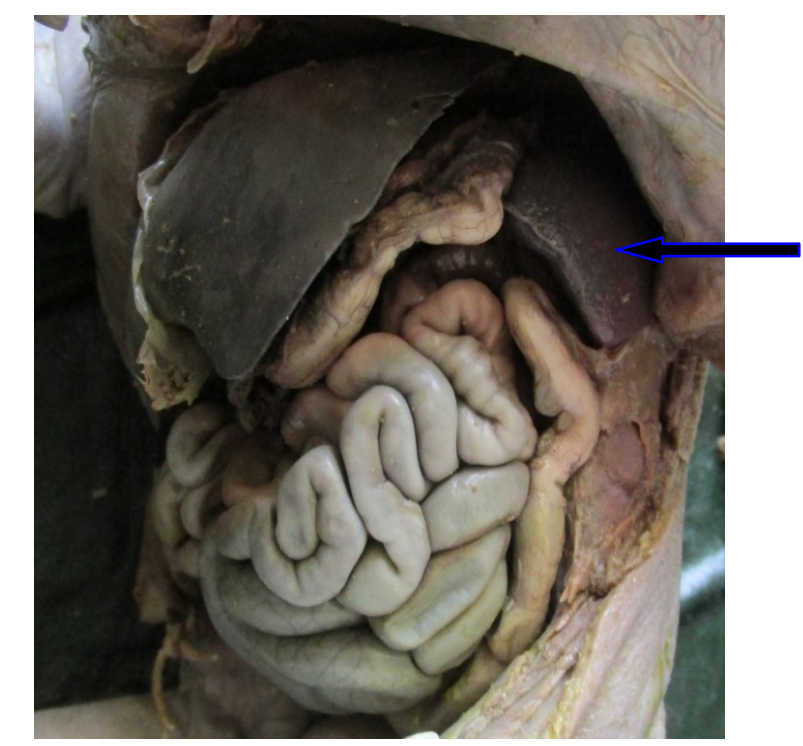

Gastrosplenic and lienorenal ligaments were universally present in all the fetal spleen studied. The phrenicocolic ligament was found in $65 \%$ cases (Fig 4 ). 
Maximum number of notches was present on the superior border of the spleen ( $n=37 ; 92.5 \%)$. The number of notches present on the fetal spleen ranged from 1 to 5 . In 3 spleens there were no notches present. Fissures were present in 11 fetal spleens (Table 4, Fig 5, 6).

Fig. 2: Wedge shape of the spleen (most common finding).

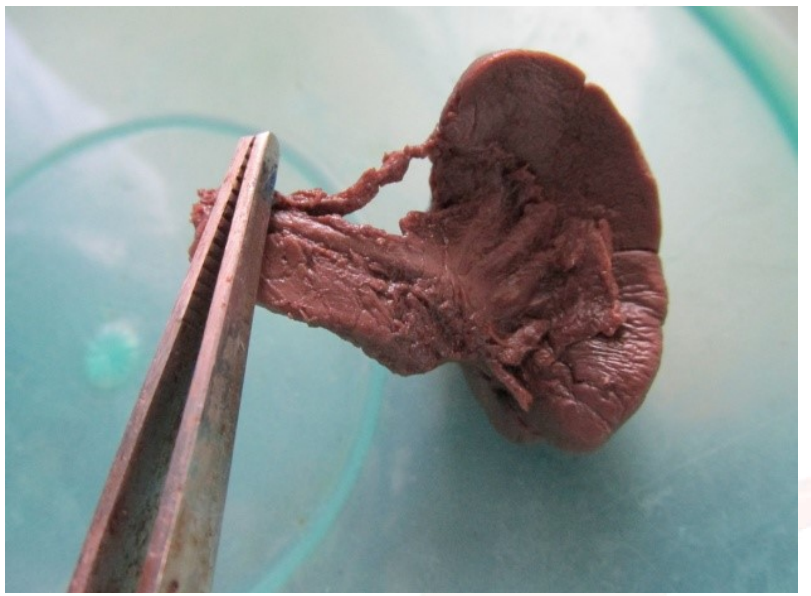

Fig. 3: Pie graph showing the distribution of shapes of the fetal spleen.

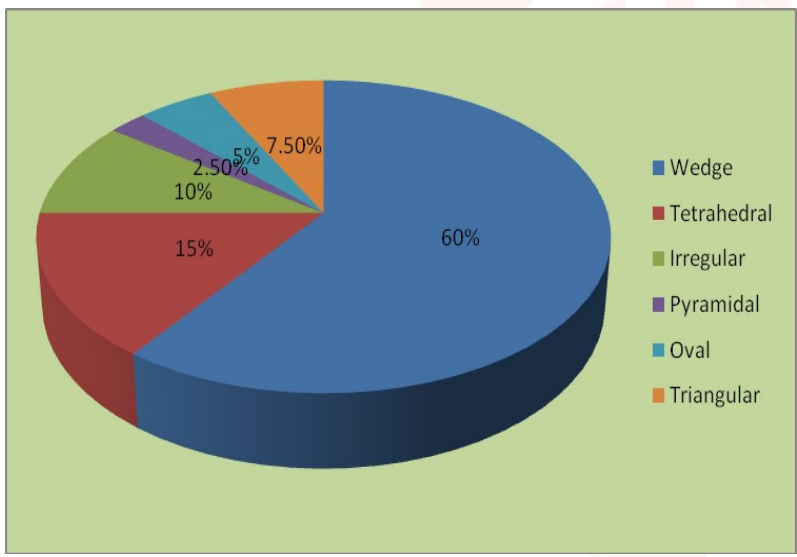

Fig. 4: Showing the gastrosplenic (red arrow) and lienorenal ligaments (blue arrow) associated with spleen in dissected fetuses.

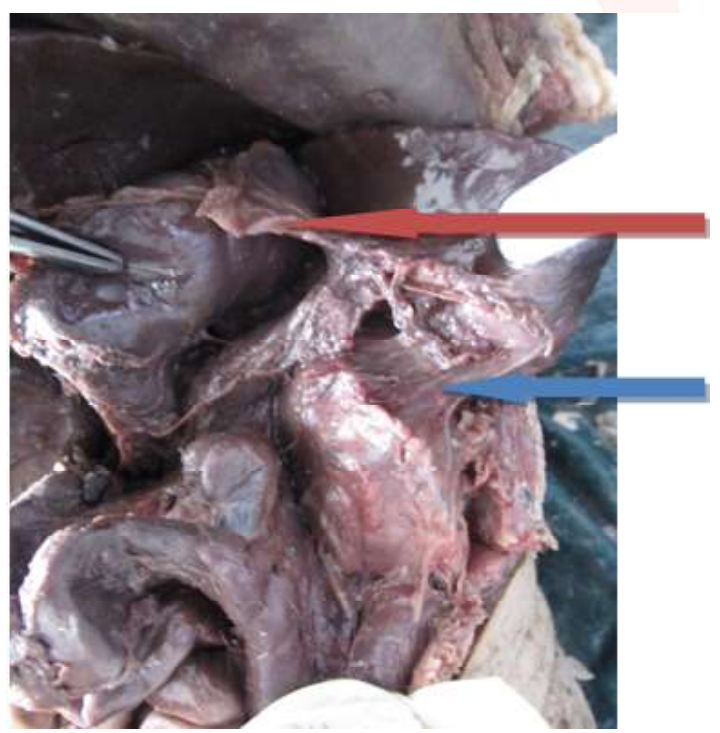

Fig. 5: Bar graph showing distribution of notches present on different borders of fetal spleen.

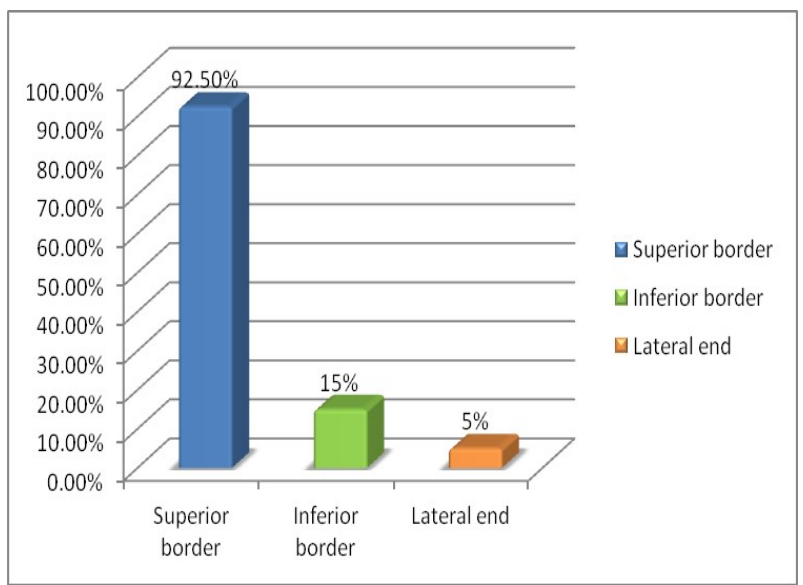

Fig. 6: Photograph showing notches and fissures on various borders of spleen.

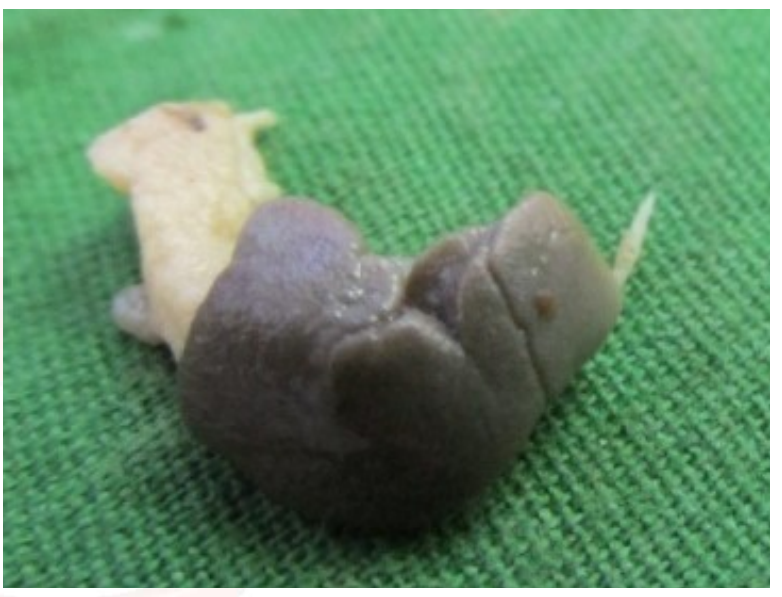

Table 1: Morphological Features Of Fetal Spleen.

\begin{tabular}{|c|c|c|}
\hline Shapes of fetal spleen & $\begin{array}{c}\text { Number } \\
(\mathbf{n}=\mathbf{4 0})\end{array}$ & Percentage \\
\hline Wedge shaped & 24 & 60 \\
\hline Tetrahedral & 6 & 15 \\
\hline Irregular & 4 & 10 \\
\hline Pyramidal & 1 & 2.5 \\
\hline Oval & 2 & 5 \\
\hline Triangular & 3 & 7.5 \\
\hline Total & 40 & $100.00 \%$ \\
\hline
\end{tabular}

Table 2: Association of shapes of the fetal spleen with the gestational age.

\begin{tabular}{|c|c|c|c|c|c|c|c|}
\hline Groups & $\begin{array}{c}\text { Wedge } \\
\mathrm{n}(\%)\end{array}$ & $\begin{array}{c}\text { Tetrahedral } \\
\mathrm{n}(\%)\end{array}$ & $\begin{array}{c}\text { Irregular } \\
\mathrm{n}(\%)\end{array}$ & $\begin{array}{c}\text { Pyramidal } \\
\mathrm{n}(\%)\end{array}$ & $\begin{array}{c}\text { Oval } \\
\mathrm{n}(\%)\end{array}$ & $\begin{array}{c}\text { Triangular } \\
\mathrm{n}(\%)\end{array}$ & Total \\
\hline $\begin{array}{c}\text { Group-1 } \\
(12-24 \mathrm{wks})\end{array}$ & $9(69.2 \%)$ & $1(7.7 \%)$ & $2(15.4 \%)$ & 0 & 0 & $1(7.7 \%)$ & 13 \\
\hline $\begin{array}{c}\text { Group-2 } \\
(25-36 \mathrm{wks})\end{array}$ & $6(42.9 \%)$ & $2(14.3 \%)$ & $2(14.3 \%)$ & $1(7.1 \%)$ & $2(14.3 \%)$ & $1(7.1 \%)$ & 14 \\
\hline $\begin{array}{c}\text { Group-3 } \\
\text { (37-40wks) }\end{array}$ & $9(69.2 \%)$ & $3(23.1 \%)$ & 0 & 0 & 0 & $1(7.7 \%)$ & 13 \\
\hline Total & 24 & 6 & 4 & 1 & 2 & 3 & 40 \\
\hline \multicolumn{7}{|c|}{$p^{*}$ value is $0.311, \mathrm{df}=10$} \\
\hline
\end{tabular}

*Chi sq likelihood ratio value is 11.620 
Table 3: Group wise correlation of different organ relations and impressions on the surface of fetal spleen.

*Multiple responses

\begin{tabular}{|c|c|c|c|c|}
\hline Organ Related * & Number/\% & $\begin{array}{c}\text { Group 1 } \\
(\mathbf{1 2 - 2 4} \text { weeks); } \\
\mathrm{n}=\mathbf{1 3}\end{array}$ & $\begin{array}{c}\text { Group 2 } \\
(\mathbf{2 5 - 3 6} \text { weeks); } \\
\mathrm{n}=\mathbf{1 4}\end{array}$ & $\begin{array}{c}\text { Group 3 } \\
(\mathbf{3 7 - 4 0} \text { weeks); } \\
\mathrm{n}=\mathbf{1 3}\end{array}$ \\
\hline Stomach & $40 / 100 \%$ & 13 & 14 & 13 \\
\hline Kidney & $34 / 85 \%$ & 7 & 14 & 13 \\
\hline Adrenal & $8 / 20 \%$ & 8 & 0 & 0 \\
\hline Colon & $38 / 95 \%$ & 11 & 14 & 13 \\
\hline Pancreas & $37 / 92.5 \%$ & 10 & 14 & 13 \\
\hline Liver & $10 / 25 \%$ & 2 & 3 & 5 \\
\hline
\end{tabular}

Table 4: Distribution of notches and fissures on borders of fetal spleen.

\begin{tabular}{|c|c|c|}
\hline Notches present at & Number $(=\mathrm{n})$ & Percentage (\%) \\
\hline Superior border & 37 & 92.5 \\
\hline Inferior border & 6 & 15 \\
\hline Lateral end & 2 & 5 \\
\hline Number of Fissures & & \\
\hline $\mathbf{1}$ & 28 & 70 \\
\hline $\mathbf{2}$ & 11 & 27.5 \\
\hline $\mathbf{0}$ & 3 & 7.5 \\
\hline Total & 40 & 100 \\
\hline
\end{tabular}

\section{DISCUSSION}

In the present study the spleen was present in the left hypochondrium region in all the fetuses studied at different gestational ages. The findings in location are in agreement with observations of Ungor et al [6], Saheb et al [7], .
Mukhia et al [8], Radhika et al [9], and Singh and Kumari [10], who studied on human fetuses The shape of the spleen is largely moulded by the surrounding structures. In the present study, majority of shape of spleen was wedge shaped (60\%) followed by tetrahedral (15\%), irregular (10\%), triangular (7.5\%), oval (5\%) and pyramidal (2.5\%). No association was found in various shapes of fetal spleen with that of gestational age. In the third group ( 37 - 40 weeks) the distribution of shapes was almost similar to those in adults, wedge shape in majority followed by tetrahedral and triangular. Our results have been compared with 6 other studies made on fetuses $[6,9,11]$ as well as adults $[12,13]$. The difference shows that the shape of the spleen develops furthermore at the postnatal period (Table 5).

Table 5: Showing comparison of various shapes of spleen of the present study with other studies.

\begin{tabular}{|c|c|c|c|c|c|c|}
\hline Shape & $\begin{array}{c}\text { Chaware et al } \\
\text { (2012) (Adult) }\end{array}$ & $\begin{array}{c}\text { Ungor et al } \\
\text { (2007) (Fetal) }\end{array}$ & $\begin{array}{c}\text { Chaudhari et al } \\
\text { (2014) (Adult) }\end{array}$ & $\begin{array}{c}\text { Sudharani et al } \\
\text { (2015) (Fetal) }\end{array}$ & $\begin{array}{c}\text { Radhika et al } \\
\text { (2016) (Fetal) }\end{array}$ & $\begin{array}{c}\text { Present Study } \\
\text { (Fetal) }\end{array}$ \\
\hline Wedge & $61.26 \%$ & $60 \%$ & $32.25 \%$ & $75 \%$ & $48 \%$ & 60.5 \\
\hline Tetrahedral & $21.62 \%$ & $36.50 \%$ & $33.87 \%$ & $25 \%$ & $24 \%$ & $15 \%$ \\
\hline Triangular & $12.61 \%$ & $3.50 \%$ & $19.35 \%$ & & $28 \%$ & $7.50 \%$ \\
\hline Oval & $3.60 \%$ & & $8.06 \%$ & & & $5 \%$ \\
\hline Irregular & $0.90 \%$ & & $6.45 \%$ & & & $10 \%$ \\
\hline
\end{tabular}

Concerning the notches on the borders, in the present study the superior border had the highest values of the incidence ratio of having notch (92.5\%). This was followed by the inferior border $(15 \%)$ and lateral end or anterior extremity (5\%). The number of notches ranged from 1 to 5. The findings of present study were similar to Ungor et al [6], Sudharani et al [11] and Radhika and Vijayanirmala [9].

In general, the notches were more in number and greater in depth in the superior border, as compared to the inferior and anterior/ lateral end. The reasons for notches of human spleen could be due to remnants of an ancestral arrangement such as lobulation or they are formed by some mechanical cause connected with growth of spleen and surrounding viscera [14]. Perhaps, notching is correlated with the increased size of the organ.

In the present study, there were $7.5 \%$ of unnotched spleens. This could mean that there was a perfect fusion of all the splenic nodules during its development. However, not much literature is available on the presence of unnotched spleens in human beings which is considered very rare. For cases related to unnotched spleens, physicians may mislead splenomegaly as renal swelling at left costal 
margin [15].

In the present study fissures were present in $30 \%(n=12)$ of cases which affected the diaphragmatic surface. Ungor et al [6] observed the percentage of fissures affecting the diaphragmatic as well as visceral surface of fetal spleens to be $7.8 \%$ and $3.5 \%$ respectively. The presence of fissure may be due to developmental defect or due to mechanical pressure from the surrounding structures [15]. The appearance of fissures on the spleen may mislead the surgeons as a traumatic injury [15].

When the neighbourhood of the spleen was in question there have been some differences from those of adults. Relation of spleen with the stomach and diaphragm was consistent with adults, but it was not the same with the other organs. The gastric impression was seen as largest and most concave visceral impression situated between the superior border and hilum of the spleen. Our findings are similar to literature review on adult spleens $[1,16]$ as well as on fetal spleens as observed by Radhika et al [9]. On the diaphragmatic surface of spleen, distinct impressions of ribs were not present in our study. This finding is similar to those reported by Sudharani et al [11] and Ungor et al [6].

When we looked at the relation of the spleen with the large intestine, it was observed that the left colic flexure was not in contact with spleen in 2 cases in the $2^{\text {nd }}$ trimester but the contact was present in the succeeding weeks almost similar to the findings of Ungor et al [6]. By this finding we have concluded that the left colonic flexure comes to its real place in the second trimester.

It was observed that the left adrenal gland was in contact with spleen in 7 out of 13 cases in the $2^{\text {nd }}$ trimester ( $1^{\text {st }}$ group) and was not in contact in the subsequent gestational ages. The textbooks concerning the adult cases have reported that the left suprarenal gland was generally not in contact with the spleen [1].

Ungor et al [6] observed that there was contact between left kidney and spleen in 62 (44\%) cases while there was no contact in $79(56 \%)$ cases. With the increase of gestational age, percentage value of contact was also increased. They also observed left adrenal gland to be in contact with the spleen in all gestational ages. This difference may be because the suprarenal gland in the fetal period is relatively bigger than it was in the postnatal period.

Concerning the relation of spleen with the pancreatic tail, in the present study it was in contact with the spleen at the region of hilum in $92.5 \%$ of cases. Interest in the proximity of these two organs lays in the possibility of damaging the pancreatic tail which has maximum number of Islet of langerhans during the course of splenectomy.

Concerning the adults, the liver has been reported to be in contact with the spleen rarely $[1,16]$. However in our study, the liver and spleen were in contact in $25 \%$ of cases of which the percentage of contact was highest in the $3^{\text {rd }}$ group (37- 40 weeks). In most cases the liver overlapped the spleen and produced an impression on the diaphragmatic surface of spleen, this was probably because fetal liver was relatively bigger than liver of adults.

In our study we have considered three of the ligaments of the spleen in which gastrosplenic and lienorenal ligaments were present in all cases. Phrenicocolic ligament was not present in $35 \%$ of cases majority in the $1^{\text {st }}$ group (12- 25 weeks) of fetuses studied. Our results are similar to the results of Ungor et al [6]. They interpreted this observation as left colic flexure has not settled to its real location yet at the early fetal period.

\section{CONCLUSION}

Knowledge of morphogenesis of spleen is important as it functions as both haematopoietic as well as lymphopoietic organ in fetal life. The notches of spleen on the superior border are palpated to diagnose splenomegaly therefore its study will form a basis for physicians. Different organ relations with the spleen help in knowledge of their development during fetal life. Due to paucity of literature about the morphological development of spleen, this study will pave a way for further research as well help in clinical practice in paediatric medicine and surgery.

\section{ACKNOWLEDGEMENTS}

We thank Dr. Mehar Bano (Assistant professor, Department of Community medicine) for helping with the statistical work. We would also like 
to express our heartfelt gratitude to $\mathrm{Dr}$ N.K. Arora (HOD Anatomy, SRMS IMS) for his invaluable suggestions regarding this paper. We would like to thanks our family for supporting us throughout this research work.

\section{Conflicts of Interests: None}

\section{REFERENCES}

[1]. Standring S. Spleen. Gray's Anatomy. The Anatomical Basis of the Clinical Practice. 40th edition. Edinburgh: Elsevier Churchill Livingstone; 2008: 1239-44.

[2]. Moore KL, Persaud TVN, Torchia MG. The digestive system. The developing human: Clinically oriented embryology: $8^{\text {th }}$ edition. New York, New Delhi: Elsevier publication; 2008: 224.

[3]. Sadler TW. Langman's Medical Embryology. $\quad 12^{\text {th }}$ edition. Philadelphia: Wolters Kluwer, Lippincott Williams \& Wilkins; 2012: 213.

[4]. Ajmani. Practical embalming. Textbook of 'Embalming principles and legal aspects'. $1^{\text {st }}$ edition. New Delhi: Jaypee publishers; 1996: pp 131-135.

[5]. Romanes GJ. The abdominal cavity. In: Cunningham manual of practical anatomy. $15^{\text {th }}$ edition. New York: Oxford university press; 2008;126-127.

[6]. Üngör B, Malas MA, Sulak O, Albay S. Development of spleen during the fetal period. Surg Radiol Anat 2007;29:543-550.

[7]. Saheb H, Velichety SD, Haseena S. Morphological and Morphometric study of Human Foetal Spleen. Int J Anat Res. 2014; 2(1):234-38.

[8]. Mukhia R, Mukherjee A, Sabnis A. Histogenesis of Human Fetal Spleen. Int J Anat Res 2016; 4 (1):21192124.
[9]. Radhika D, Vijayanirmala B. Morphometry of spleen. J. Evid. Based Med. Healthc. 2016; 3(28):1297-1300.

[10]. Singh R, Kumari G. Morphological Assessment of Human Foetal Spleen. Asian Journal of Biomedical and Pharmaceutical Sciences,2016;6(52):19-21.

[11]. Sudharani K, Usha M, Ratnachary P. A Study of Regional Anatomy of Spleen. Journal of Evidence based Medicine and Healthcare. April 13, 2015; 2 (15): 2125-2133.

[12]. Chaudhari ML, Maheria PB, Lakhani C, Menezes VR. Morphological Variations of Human Spleen and its Clinical Significance. Int J Med Res Rev.2014; 2(1):16-20.

[13]. Chaware PN, Belsare SM, Kulkarni YR, Pandit SV, Ughade JM. The Morphological Variations of the Human Spleen Journal of Clinical and Diagnostic Research. April 2012; 6(2): 159-162.

[14]. Das S, Latiff AA, Suhaimi FH, Ghazali H, Othman F. Anomalous splenic notches: a cadaveric study with clinical importance. Bratisk Lek Listy. 2008; 109 (11): 513- 516

[15]. Setty SNRS, Katikireddi RS. A cadaveric study of human splenic notches and fissures. Int J Health Sci Res. 2013; 3(9):40-44.

[16]. Moore KL, Dalley AF, Agur AMR. Spleen in Abdomen. Clinically oriented anatomy. $6^{\text {th }}$ edition. New Delhi: Wolters Kluwers (India) pvt Itd 2010;263-265.

How to cite this article:

Thomas S, Sinha DN, Singh AK, Deopa D, Niranjan R. MORPHOLOGICAL CHANGES IN HUMAN FETAL SPLEEN AT DIFFERENT GESTATIONAL AGES. Int J Anat Res 2019;7(3.3):69706975. DOI: 10.16965/ijar.2019.273 